\title{
Cost-benefit of COVID-19 lockdown in the UK
}

Economic costs of continuing severe COVID-19 lockdown restrictions in the UK now appear to be so great relative to lives saved by averting COVID-19 infections that easing restrictions has become warranted, said authors of a costbenefit analysis published in the International Journal of Clinical Practice.

The response to and outcomes of the COVID-19 pandemic in the UK were compared with the response and outcomes in ten countries in Europe with average annual incomes of $£ 15000$ per person. Economic costs were estimated in terms of percentage loss in national gross domestic product (GDP) relative to the benefits of avoiding lifeyears lost.

The severity and timing of COVID-19 lockdown restrictions varied widely between the UK and other countries in Europe, but there was less variation in mortality rate, which decreased in all countries in May/June 2020. After adjustment of comordidities and QOL, it was estimated that 5 QALYs were lost per death from COVID-19.

The UK the Office for Budget Responsibility, and the Bank of England, estimated in May 2020 that the UK GDP would be $13 \%-14 \%$ lower in 2020 than in 2019 . The lowest estimate for costs incurred during lockdown was $40 \%$ greater than the maximum benefits from avoiding worst-case mortality.

Based on 60000 excess deaths in the UK from COVID-19, 10130 patients admitted to intensive care units and 125000 hospital admissions, estimated total hospitalisation costs were $£ 9000$ per excess death.

It was estimated that the cost per QALY gained necessary to justify continuing lockdown in the UK would be $£ 220000$ in the best-case scenario and $£ 3.7$ million in the worst-case scenario ( 7 and 125 times the NICE* guideline of $£ 30000$ per QALY gained, respectively).

"Movement away from blanket restrictions that bring large, lasting and widespread costs and towards measures targeted specifically at groups most at risk is now prudent. Such a policy has now been implemented," said the authors.

* National Institute for Health and Care Excellence

Miles D, et al. "Stay at Home, Protect the National Health Service, Save Lives": a cost benefit analysis of the lockdown in the United Kingdom. International Journal of Clinical Practice : e13674, 13 Aug 2020. Available from: URL: http://doi.org/10.1111/ijcp.13674 